\title{
Angular Spectral Analysis and Lowpass Filtering of Aeromagnetic Data Over Western Parts of Bornu Basin of Nigeria
}

\author{
${ }^{1} \mathrm{Y}$. A. Sanusi and 20. K. Likkason \\ 1 Department of Physics, Usmanu Danfodiyo University, P. M. B. 2346, Sokoto \\ 2 Physics Programme, Abubakar Tafawa Balewa University, P. M. B. 0248, Bauchi \\ [ ${ }^{\star}$ Corresponding author: Email: hidima05@gmail.com, P: 08032844005]
}

\section{ABSTRACT}

Total-field aeromagnetic data over the western half of the Bornu basin and its surrounding areas were analyzed using angular spectral analysis, upward continuation and lowpass filtering techniques. Results revealed several angular spectral peaks at various angular orientations. The angular orientations correlated with the trends of the deep-seated NNW-SSE, NW-SE, NNE-SSW and NE-SW regional lineaments inferred from the upward continuation and lowpass filtering techniques. Superposition of the inferred regional lineaments on the surface geology suggests that the inferred lineaments exerted structural control on the magmatism, sedimentation pattern and the flow pattern of the Gongola river in the study area.

Keywords: Bornu basin, upward continuation, lowpass filtering, angular spectral analysis, lineaments.

\section{INTRODUCTION}

The Chad basin is a large intracratonic inland basin within the Central West Africa that covers an aerial extent of about 2,335,000 km2 and extends into five countries namely, Nigeria, Niger Republic, Chad Republic, Cameroon and Central African Republic. The Bornu basin, which forms part of the West and Central African System (WCARS), is located in the northeastern part of Nigeria and constitutes about one-tenth of the aerial extent of the entire Chad basin. The basin borders the basement complex of northern Nigeria to the west and southwest and the Benue Trough to the south (Figure 1). The Bornu basin together with the Benue Trough, the Bida basin, the Sokoto basin and the Anambra basin constitute another set of a series of Cretaceous and younger rift basins in Central and West Africa whose origin is related to the opening of the South Atlantic (Obaje et al., 2004).

Data obtained from magnetic surveys are displayed either as contour or colour shaded relief maps or both. The contour maps present the amplitude of the magnetic anomalies as contour closures or contour lines while colour shaded maps present them as colour aggregates. Magnetic anomalies represent the various effects of the variations in magnetic polarization within the subsurface (Kearey et al., 2002). Anomalies produced by near-surface magnetic bodies are of short wavelength while those from the deeper sources are smoother and of long wavelength. More often, in areas associated with near surface and/or exposed basement terrains, the short wavelength anomalies obliterate the long wavelength anomalies thus rendering the interpretation of the long wavelength anomalies extremely difficult.

One of the greatest advantages of potential field data is that it can be used to enhance selected anomalies associated with certain wavelengths at the expense of other anomalies using frequency domain based filtering operations. Filters that enhance short wavelength anomalies at the expense of long wavelength anomalies are termed highpass filters while filters that enhance long wavelength anomalies at the expense of short wavelength anomalies are termed lowpass filters. Thus, to enhance deeper or regional structures, anomalies associated with longer wavelengths are enhanced at the expense of the short wavelength anomalies, using Fourier domain based operations of upward continuation and lowpass filtering processes. 


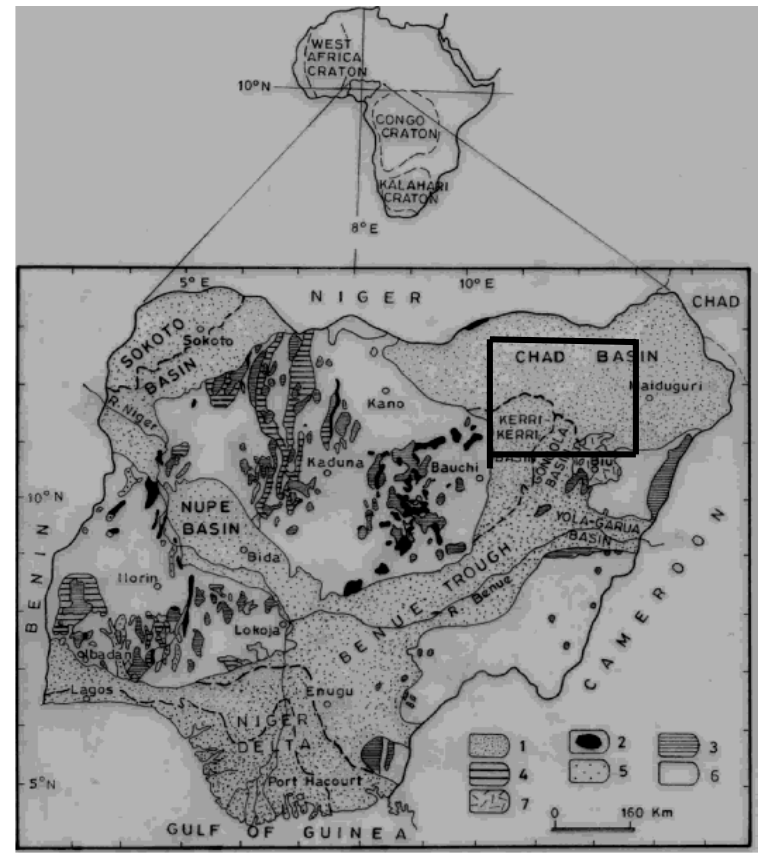

Figure1. Map of Nigeria showing the location of the study area.

Previous studies in the study area suggested that the Bornu basin may contain thick sediments and structural traps in form of linear and curve-linear structures both of which are clues for hydrocarbon potential (Avbovbo et al., 1986; Ibe, 2000; Lawal, 2005; Sanusi and Likkason, 2011; Emmanuel and Augustine, 2012; Sanusi and Likkason, 2015). According to Sanusi and Likkason (2011), the magnetic sources in the western part of the Bornu basin were classified as intra-sedimentary sources buried at average depths from 0.62 to $1.60 \mathrm{~km}$, basement structures at depths from 2.7 to $4.36 \mathrm{~km}$ and deeper magnetic sources at average depth from 37.6 to $39.7 \mathrm{~km}$. As a follow-up to this study (Sanusi and Likkason, 2011), the methods of angular spectral analysis, lowpass filtering and upward continuation were employed to analyze the aeromagnetic data over the study area bounded between longitudes $10.00^{\circ} \mathrm{E}$ to $12.50^{\circ} \mathrm{E}$ and latitudes $11.50^{\circ} \mathrm{N}$ to $13.50^{\circ} \mathrm{N}$ (Figure 1) with the aim of delineating the nature of the deep-seated structures associated with the long wavelength anomalies and their geologic implications in the study area.

\section{Brief Geology}

Sedimentation in the Bornu basin commenced in the Upper Cretaceous during which continental sandstone consisting of granitic inliers (Bima basin) was deposited on the basement mainly to the south-west of the basin (Barber, 1965). The basal beds of the Bima sandstone are invariably feldspathic while the upper beds are less feldspathic (Matheis, 1976). An extensive transgression later, in the Turonian, followed alongside with the deposition of the mixed limestone/shale sequence (Gongila Formation). A marine incursion began towards the end of the Turonian up to the Senonian during which the blue-black marine shales known as the Fika shales, exposed in the southeastern part of the study area were deposited. An estuarine-deltaic environment later followed towards the end of the Cretaceous and the Gombe sandstone was deposited with intercalations of siltstones, shales and ironstones (Furon, 1963). The Kerri- kerri Formation, which is exposed in the southcentral part of the study area, was later deposited in the Paleistocene and finally the Chad Formation, dated as Quartenary and exposed in the northern and upper southeastern part of the study area (Durotoye, 1976) was deposited. Other Formations exposed in the study area include the Gundumi and Yolde Formations which are exposed in the southeastern part of the study area. However, the Precambrian basement complex rocks in the study area were exposed in the SE and SW parts of the Istudy area. These rocks consist of basalts, older granites and gneiss-migmatite complex. The surface geology of the study area is shown in Figure 2.

\section{Brief Theory}

A 2-D spectrum can be expressed in condensed form as a 1-D spectra of angular and radial spectra (Spector and Grant, 1970; Naidu and Mathew ,1998). According to Naidu and Mathew (1998), the spectrum of the magnetic field caused by a layer of random magnetization may be expressed as;

$S_{f t}=|\Gamma(u, v)|^{2} S_{\kappa}(u, v) \frac{\exp (-2 h s)}{s^{2}}$ 


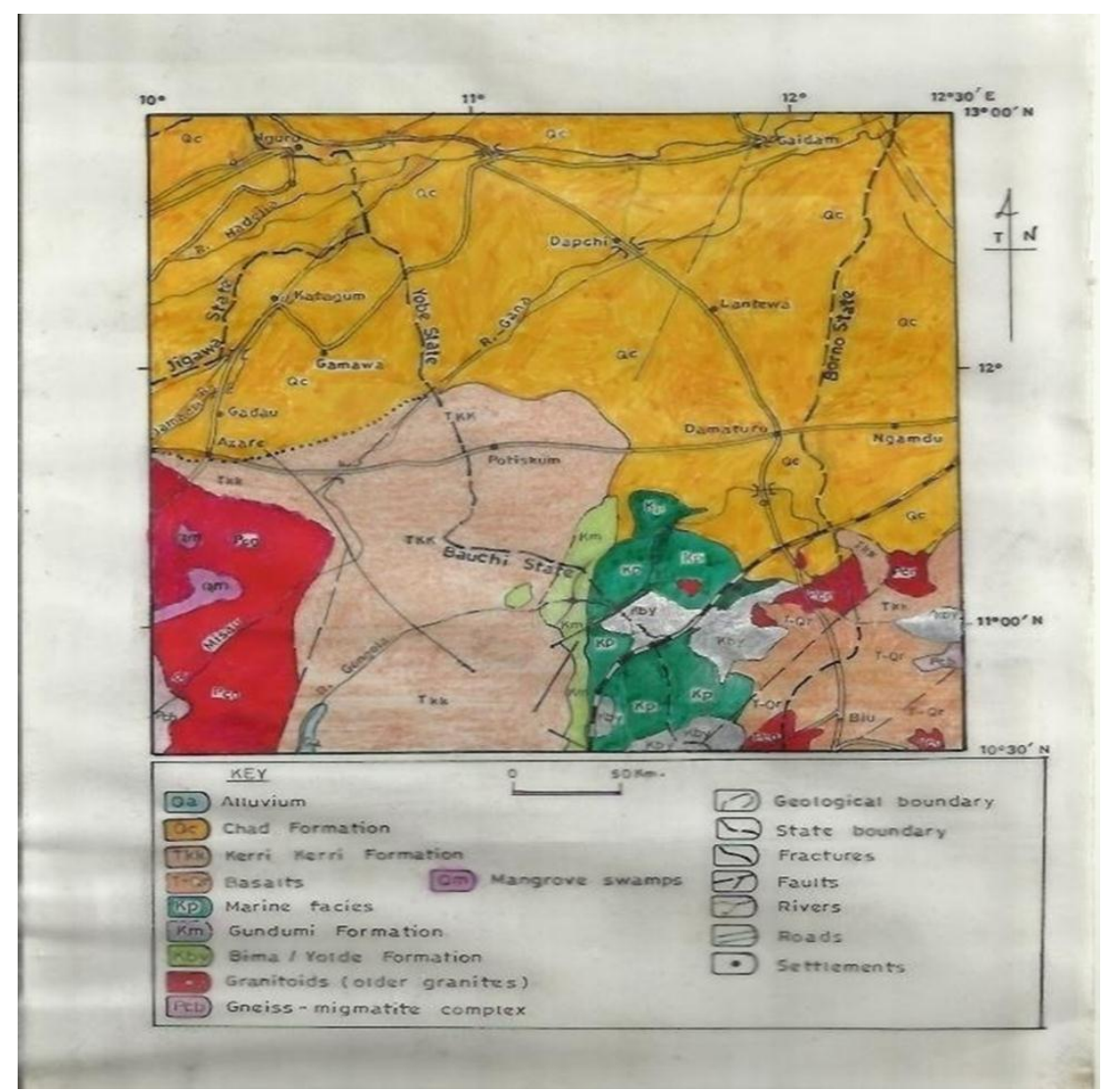

Figure 2. The surface geology map of the study area

$S_{\kappa}(u, v)$ denotes the source spectrum, $u$ and $v$ are frequencies along $x$ and $y$ directions, $s$ is the magnitude of the frequency vector expressed as, $s=\sqrt{\left(u^{2}+v^{2}\right)}, \mathrm{h}$ is the depth to the top of the magnetic layer, and $\Gamma(u, v)$, represent physical property of the magnetic field.

Assuming uncorrelated random magnetization and the direction of the inducing field as the same as the present Earth's magnetic field, $|\Gamma(u, v)|^{2}$ can be expressed as (Naidu and Mathew, 1998):

$$
|\Gamma(u, v)|^{2}
$$$$
=I_{0}^{2} s^{4}\left[\gamma^{2}+\left(\alpha^{2}+\beta^{2}\right) \cos ^{2}\left(\theta-\theta_{0}\right)\right]^{2}
$$

where ${ }^{I_{0}}$ is the direction of the present Earth's magnetic field, $\theta$ is the direction of the frequency vector in the spatial frequency plane, $u$ and $v_{\text {(in }}$ $\mathrm{rad} / \mathrm{km})$, along $x$ and $y$ directions often expressed as: $\theta=\tan ^{-1}\left(\frac{u}{v}\right)$ and $\theta_{0}$ is the declination of the Earth's magnetic field and $\alpha, \beta$ and $\gamma$ are directional cosines of the Earth's magnetic field. Finally, substituting equation (2) into equation (1) yields the following equation (Naidu and Mathew, 1998):

$$
S_{t f}(u, v)=e^{-2 h s} I_{0} s^{4}\left[\gamma^{2}+\left(\alpha^{2}+\beta^{2}\right) \cos ^{2}\left(\theta-\theta_{0}\right)\right]^{2}
$$

Using equation (3), Naidu and Mathew (1998) showed that the angular spectrum may be expressed as:

$$
A_{\text {norm }}(\theta)=\Omega\left[\gamma^{2}+\left(\alpha^{2}+\beta^{2}\right) \cos ^{2}\left(\theta-\theta_{0}\right)\right]^{2}
$$

Where $\Omega$ is a constant. Based on equation (4), the angular spectrum is a maximum in the direction of the polarization vector.

In order to free the angular spectrum of any radial variation, normalization with respect to the radial 
spectrum is often applied. Thus the angular spectrum is expected to bring out the angular variations, if any, of the 2D spectrum of the potential fields.

\section{Filtering}

According to Bhattacharya (1965) the total potential field anomaly $(\Delta T)$ in a horizontal plane above the Earth's surface can be expressed as

$$
\Delta T(x, y, z)=\sum_{n=0}^{\infty} \sum_{m=0}^{\infty} \exp \left\{\begin{aligned}
\left.-2 \pi z\left(\frac{m^{2}}{L_{x}^{2}}+\frac{n^{2}}{L_{y}^{2}}\right)^{\frac{1}{2}}\right\}\left(A_{m} \cos 2 \pi m \frac{x}{L_{x}}+B_{m} \sin 2 \pi m \frac{x}{L_{x}}\right) . \\
\left(C_{n} \cos 2 \pi n \frac{y}{L_{y}}+D_{n} \sin 2 \pi n \frac{y}{L_{y}}\right)
\end{aligned}\right.
$$

Where $\mathrm{m}$ and $\mathrm{n}$ are harmonies in $\mathrm{x}$ and $\mathrm{y}$ directions, $L x$ and $L y$ are the fundamental wavelengths in the $x$ and $y$ directions and $\mathrm{Am}, \mathrm{Bm}$, $\mathrm{Cn}$ and $\mathrm{Dn}$ are coefficients in the Fourier series expansion. The fundamental wavelengths $L x$ and Ly in the two directions are expressed as (Bhattacharya, 1965):

$$
L_{x}=M S_{x} \text { and } L_{y}=N S_{y}
$$

where $\mathrm{M}$ and $\mathrm{N}$ are number of data values along the $x$ and $y$ directions respectively, while Sx and Sy are the data spacing in these directions.Bhattacharya (1965), has shown that the total potential field values in a horizontal plane $(z=$ 0 ) can be expressed, in terms of double Fourier series, as:

$$
\left.\Delta T(x, y, 0)=\sum_{m=0 n=0}^{m_{0}} \sum_{n_{0}}^{A_{m n} \cos 2 \pi m \frac{x}{L_{x}} \cdot \cos 2 \pi n \frac{n}{L_{y}}+B_{m n} \cos 2 \pi m \frac{x}{L_{x}} \cdot \sin 2 \pi n \frac{y}{L_{y}}+} \begin{array}{l}
E_{m n} \sin 2 \pi m \frac{x}{L_{x}} \cdot \cos 2 \pi n \frac{y}{L_{y}}+F_{m n} \sin 2 \pi m \frac{x}{L_{x}} \cdot \sin 2 \pi n \frac{y}{L_{y}}
\end{array}\right)
$$

Substituting equation (6) into (5) yields

$$
\Delta T(x, y, z)=\sum_{n=0}^{n_{0}} \sum_{m=0}^{m_{0}} T(x, y, 0) \cdot \exp \left\{-2 \pi z\left(\frac{m^{2}}{L_{x}^{2}}+\frac{n^{2}}{L_{y}^{2}}\right)^{\frac{1}{2}}\right\} \text {. }
$$

\section{METHODOLOGY}

Twenty-five total-field aeromagnetic maps on a scale of 1:100,000 and covering the entire study area were obtained from the Nigerian Geological Survey Agency (NGSA) for the purpose of this study. The magnetic data were collected at a nominal flight elevation of $0.15 \mathrm{~km}$ along N-S flight lines, which were spaced at $2 \mathrm{~km}$ interval, and presented in form of contour lines in the aeromagnetic sheets. To recover the raw total field magnetic data, the aeromagnetic maps were digitized at a constant spacing interval of $1.5 \mathrm{~km}$ along the flight lines. Next, the Earth's main field at each digitized point was estimated, using the 1975 Definitive Geomagnetic Reference Model (DGRF) model, and directly subtracted from the total-field magnetic intensity values to obtain the residual magnetic field of interest.

The common procedure involved in the angular spectral analysis, upward continuation and lowpass filtering methods was the conversion of the 2-D residual data set into the wavenumber domain, employing the subroutine of Claerbout (1969). The product obtained from this conversion was a 2-D Fourier transform of the input data. In the case of angular spectral analysis, the power spectrum was estimated from the 2-D transform and normalized to free it from the effects of the radial spectrum. The estimated angular spectrum was then computed, based on equation (4), as outlined in previous studies (Naidu and Mathew, 1998; Likkason, 2007; Bassey et al. ,2012).The estimated angular spectrum was subsequently averaged over three frequency sub-bands ranging from 0 - 21 low frequency, 21 - 42 mid frequency and $42-64$ high frequency subbands respectively.

In the upward continuation process, the 2-D Fourier transform was multiplied with the exponential function in equation (7) in the frequency domain, while in the lowpass filtering processes, the 2-D Fourier transform was multiplied with appropriate filter function which passes selected long wavelengths associated with low wavenumbers. In both processes, the outputs obtained in the frequency domain were inverse Fourier transformed back to the space domain. It is worth mentioning that the residual magnetic field intensity values were continued upward to a height of $40 \mathrm{~km}$ above the flight elevation to highlight the low wavenumber component reflecting the effects 


\section{Nigerian Journal of Basic and Applied Science, (December, 2016), 24(2): 73-84}

of deeper sources, interference and shallow plates sources. To compare performance and pattern, a lowpass filter of various wavelengths were applied to the residual magnetic field intensity values.

\section{RESULTS AND DISCUSSION}

The contour maps of the total-field magnetic field values and the residual magnetic field intensities (Figures 3 and 4) show that the northern part of the study area is predominantly characterized by long wavelength anomalies, which is a characteristic of sedimentary areas. However, short wavelength anomalies were observed to be superposed on the long wavelength anomalies, especially in the northcentral and extreme end of the northwestern part. This superposition suggests presence of nearsurface intra-sedimentary intrusions or basement uplift beneath these areas. In the southern part of the study area, short wavelength anomalies, which were observed to correlate with the exposed basement rocks, dominate the western and the eastern flanks while long wavelength anomalies dominate the central part. The general trends of the anomalies in the study area were observed to be aligned along ENE-WSW, NE-SW, E- W and NW-SE directions.

According to Hall (1979), these trends did not occur in random but are generally aligned along preferred axes that can be used to define magnetic sources. The trends of these anomalies seem to correlate with the general structural trends in the adjacent Benue trough and the Bida basin (Ajakaiye et al., 1986; Onyedim et al., 2009). The total-field magnetic intensity (TMI) values range from $31950 \mathrm{nT}$ to $33050 \mathrm{nT}$ while the residual magnetic intensities vary from $-1540 \mathrm{nT}$ to $-734 \mathrm{nT}$. The complete negative values for the residual magnetic field intensities were expected as the study area lies very close to the magnetic equator where the polarizing field is horizontal (Affleck, 1963; Likkason, 2004).

The graph of the computed angular spectrum (Figure 5) shows spectral peaks apparent in the low, mid and high frequency sub-bands. The graph of the low frequency subband is approximately bell shaped with a sharp peak at $90^{\circ}$ and two broad peaks at $37^{\circ}$ and $142^{\circ}$.

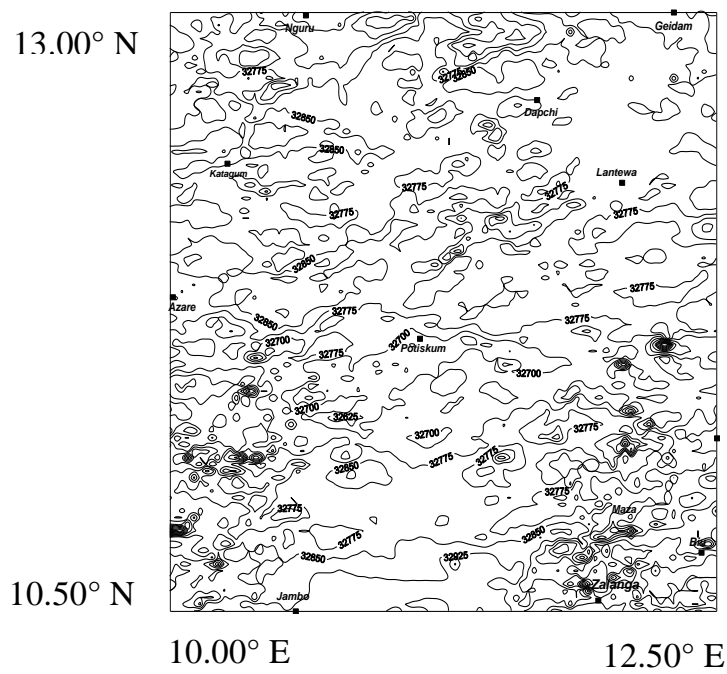

Figure 3: Total Magnetic Field Intensity values over the area (Contour interval is $75 \mathrm{nT}$ ).

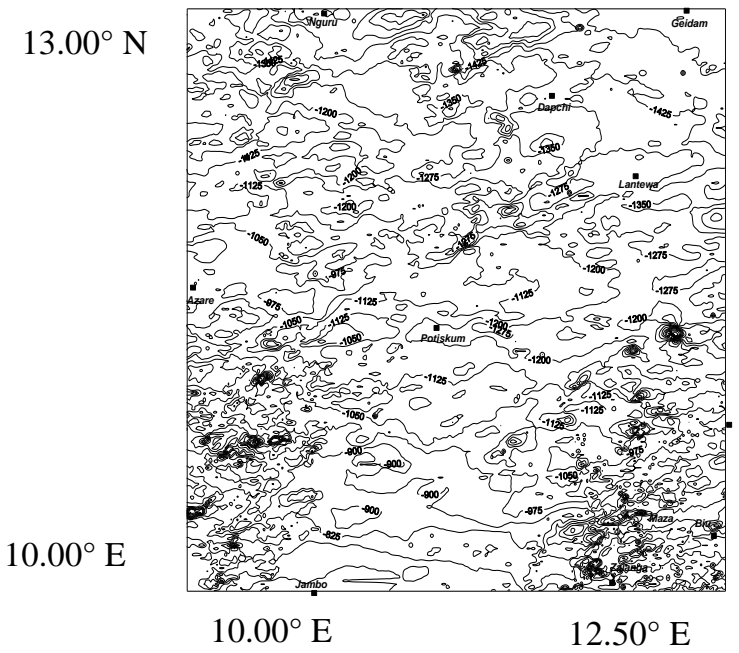

Figure 4: Residual Magnetic Field Intensity Values over the area (Contour interval is $75 \mathrm{nT}$ ).

The mid frequency sub-band has ten spectral peaks at $21^{\circ}, 25^{\circ}, 37^{\circ}, 65^{\circ}, 90^{\circ}, 133^{\circ}, 142^{\circ}$, $152^{\circ}, 162^{\circ}$ and $172^{\circ}$ while the high frequency subband has nineteen spectral peaks at $12^{\circ}, 14^{\circ}, 17^{\circ}$, $21^{\circ}, 23^{\circ}, 25^{\circ}, 37^{\circ}, 42^{\circ}, 50^{\circ}, 90^{\circ}, 146^{\circ}, 152^{\circ}$, $162^{\circ}, 165^{\circ}, 166^{\circ}, 167^{\circ}, 168^{\circ}, 170^{\circ}$ and $172^{\circ}$. There was a correspondence at $37^{\circ}$ and $90^{\circ}$ between all the three sub-bands, another correspondence at $142^{\circ}$ between the low and mid 
subbands and another correspondence at $21^{\circ}$, $25^{\circ}, 152^{\circ}, 162^{\circ}$ and $172^{\circ}$ between the mid and high frequency sub-bands. Following interpretations from previous studies (Naidu and Matthew, 1998; Likkason, 2007; Bassey et al., 2012), the spectral peak at $90^{\circ}$ was interpreted to reflect the effect of the tapered square cosine window used in the analysis, while the spectral peak at $172^{\circ}$ was interpreted to correspond to the direction of polarization of the Earth's magnetic field in the study area. The other corresponding spectral peaks at $21^{\circ}, 25^{\circ}, 37^{\circ}, 142^{\circ}, 152^{\circ}$ and $162^{\circ}$ were interpreted as faults/fractures along NNW-SSE, NW-SE, NNE-SSW and NE-SW directions. Among these trends the NE-SW structural trends were earlier inferred, based on match bandpass filtering technique, in the study area (Sanusi and Likkason, 2015). Hence, the NNW-SSE, NW-SE and NNE-SSW structural trends were interpreted as previously unmapped faults/fractures in the study area.

(a) Low subband
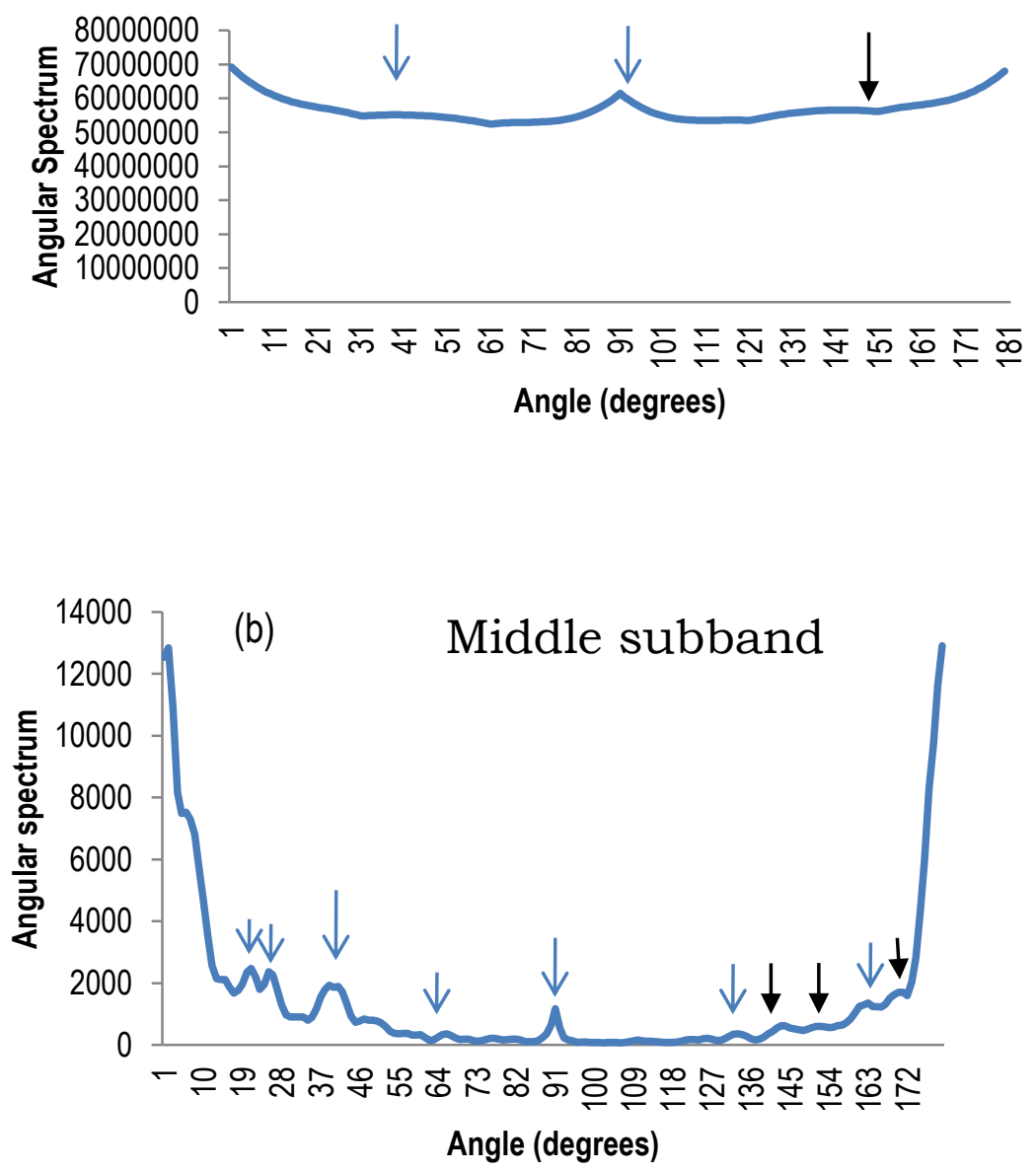
Nigerian Journal of Basic and Applied Science, (December, 2016), 24(2): 73-84

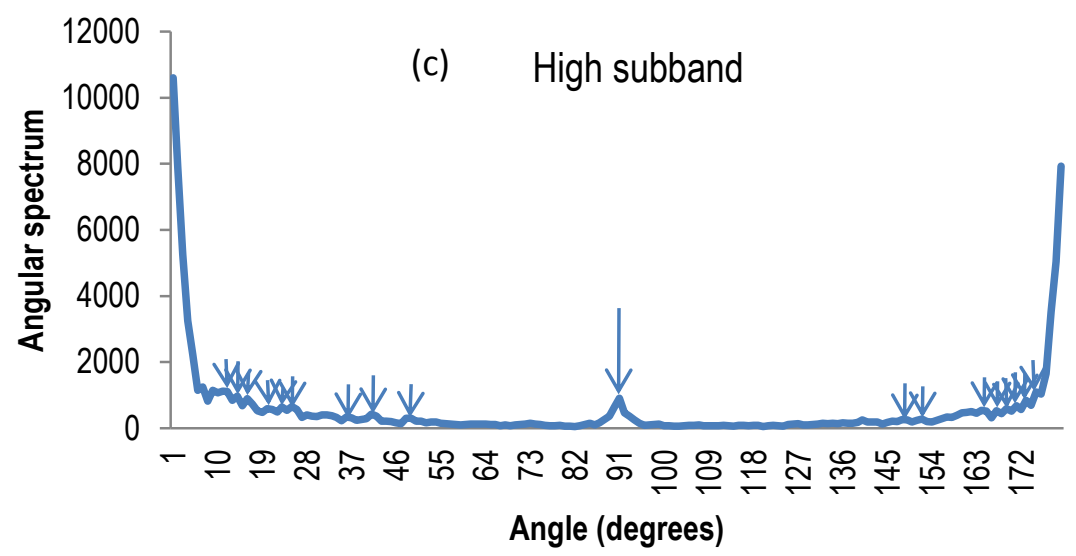

Figure 5: Angular spectra of the (a) low (b) middle and (c) high frequency sub-bands.

$10: 30 \mathrm{~N}$

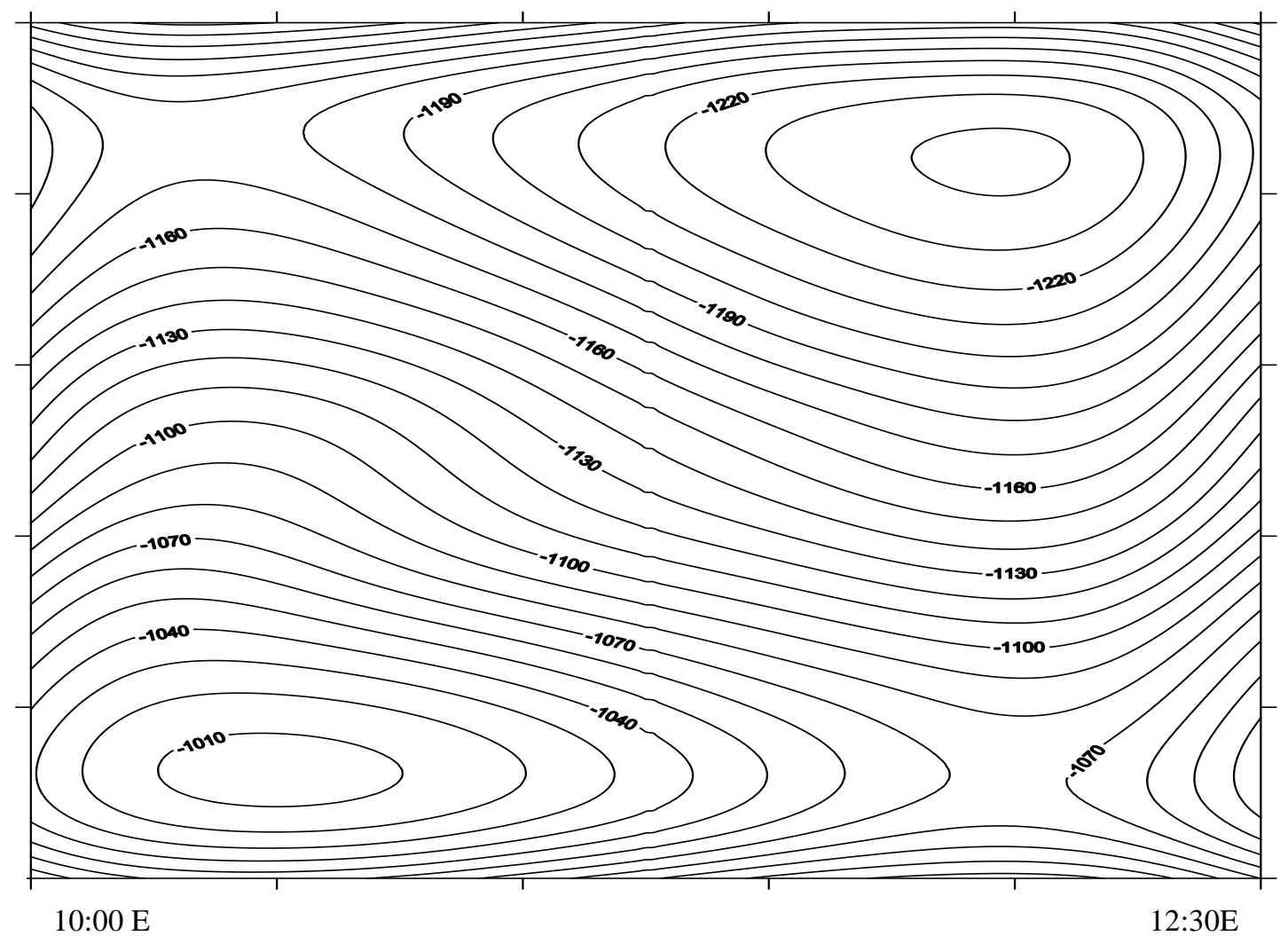

Figure 6: Contour map showing the magnetic anomaly map continued upward to a height of $40.0 \mathrm{~km}$ (Contour interval is $20 \mathrm{nT}$ ).

The contoured maps of the upward continued and lowpass filtered data (Figures 6 and 7 ), show four long wavelength anomalies, associated with two magnetic highs and two magnetic lows, interpreted to emanate from deep sources within the Earth's crust. The active centres of the magnetic high and the magnetic low in the SW and NE parts were positioned within the study area (Figure 8) while the active centers of other magnetic high and 
magnetic low were positioned slightly outside the NW and SE parts of the study area.

This resemblance in the pattern of anomalies between the upward continued and lowpass filtered maps suggests that the effect of upward continuation to a height of $40 \mathrm{~km}$, above flight elevation, is similar to lowpass filtering with a cutoff wavelength of $145 \mathrm{~km}$ in the study area. Comparison of the features in the two lowpass filtered maps and the residual magnetic field contour map (Figure 4), suggests that the residual magnetic field contour map reflect predominantly the magnetic effects of shallow and intermediate magnetic sources. Following Likkason et al. (2005), the lines joining a pair of a magnetic high and magnetic low were interpreted to reflect fault lines. Hence, four deep-seated faults $(A D, B C, A C$ and $\mathrm{BD}$ ) with orientations $\mathrm{N} 152 \circ \mathrm{E}, \mathrm{N} 162 \circ \mathrm{E}, \mathrm{N} 37 \circ \mathrm{E}$ and $\mathrm{N} 136{ }^{\circ} \mathrm{E}$, shown in Figure 8, were inferred and interpreted as the possible sources of the anomalies associated with the low wavenumber component of the residual field. Furthermore, there is correspondence between the trends of deepseated faults $A D, B C$ and $A C$ and the angular positions corresponding to three spectral peaks observed in the angular spectrum while the trend of the deep-seated fault $\mathrm{BD}$ is very close to the spectral peak at 142。. These observed correspondences suggest that the inferred deepseated faults represent the possible sources of the spectral peaks in the angular spectrum.

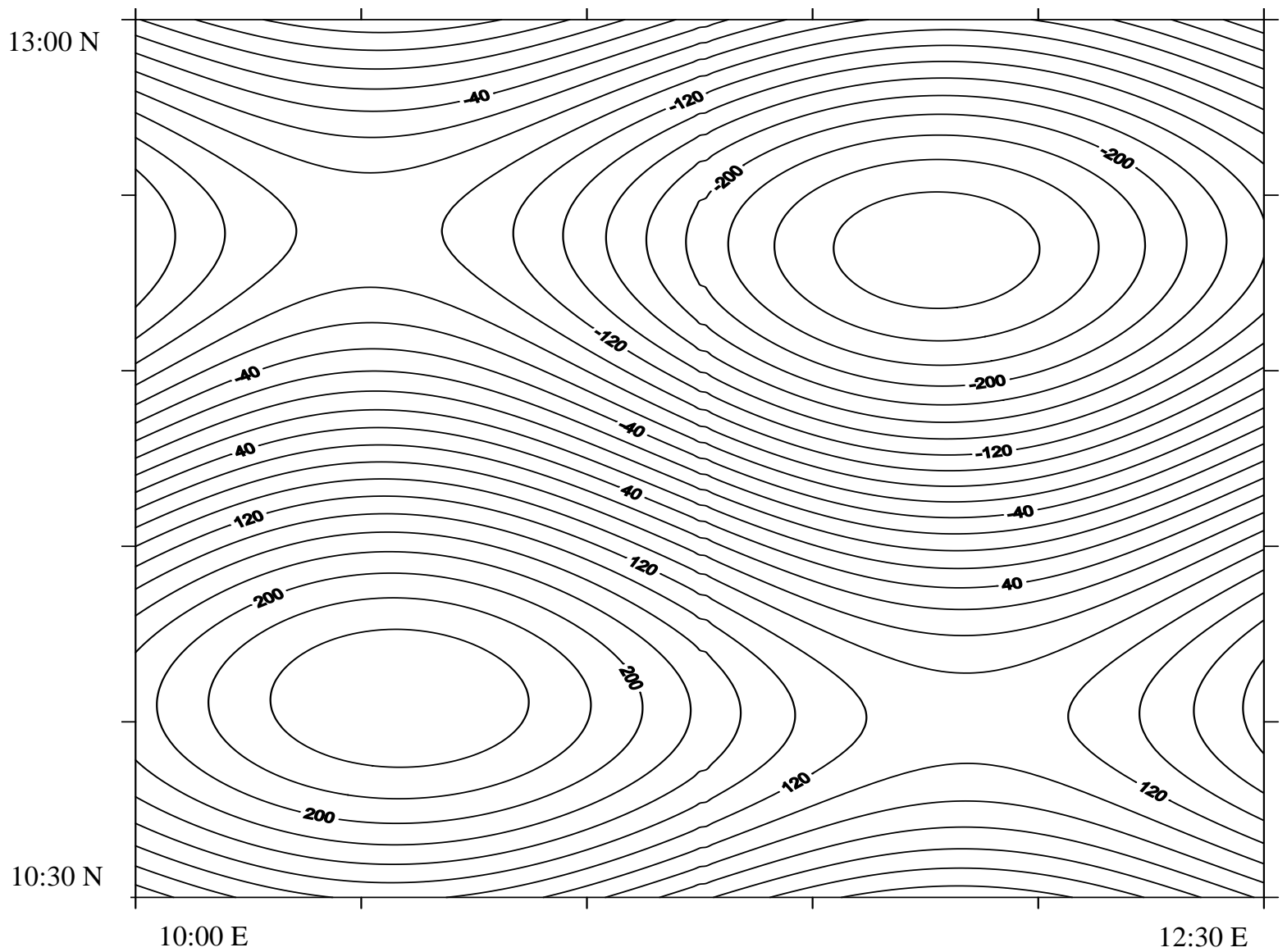

Figure 7: Contour map showing the lowpass filtered magnetic anomaly map using a cutoff wavelength of $145 \mathrm{~km}$ (Contour interval is $20 \mathrm{nT}$ ). 
Nigerian Journal of Basic and Applied Science, (December, 2016), 24(2): 73-84

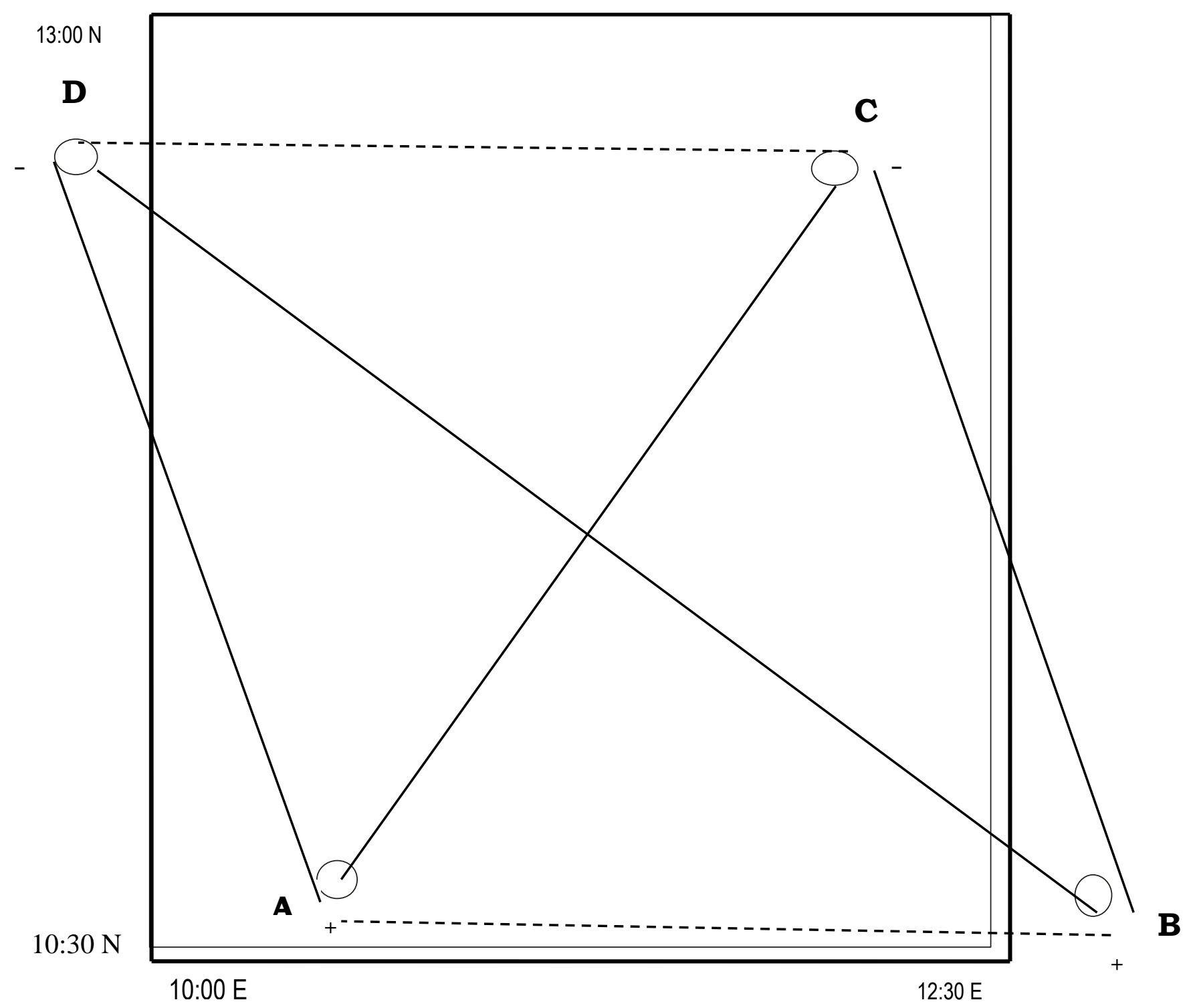

Figure 8: Schematic representation of the two magnetic dipoles deduced from upward continuation of the residual magnetic field to $40 \mathrm{~km}$ above the flight elevation. Lines $A D, B C, A C$ and $B D$ were interpreted as deep-seated faults.

The superposition of the inferred deep-seated faults on the surface geology (Figure 9), showed that two NNW-SSE strike-slip faults $F_{1}-F_{1}^{\prime}$ and $F_{2}-F_{2}^{\prime}$, correlating with fault lines $\mathrm{AD}$ and $\mathrm{BC}$ (Fig. 8), seem to be bound the study area to the $\mathrm{NE}$ and SW. The strike slip fault $F_{1}-F_{1}^{\prime}$, associated with wavelength of $140 \mathrm{~km}$, spans from the lower part of the SW part of the study area up to the area west of Gadau, cross-cutting across predominantly the basement rocks and the sedimentary portion in the SW part of the study area. The strike-slip fault $F_{2}-F_{2}^{\prime}$, associated with wavelength of $175 \mathrm{~km}$, spans from around Ngamdu up to around Geidam in the NE part of the study area, cross-cutting across purely the Chad Formation. The third strike-slip fault $\left(F_{3}-F_{3}^{\prime}\right)$ associated with a wavelength of $320 \mathrm{~km}$ and oriented along the NW-SE direction spans from the 
SE quadrant up to the NW quadrant of the study area cross-cutting both the basement complex region, in the SE quadrant, and both the Kerri-Kerri and Chad Formations in the central and NW part of the study area. The fourth fault $\left(F_{4}-F_{4}^{\prime}\right)$, oriented along NE-SW direction and associated with a wavelength of $270 \mathrm{~km}$ spans from the lower part of the SW part of the study area up to a region southeast of Geidam in the NE part of the study area with its lower segment aligned parallel to the course of River Gongola, thus structurally controlling the flow pattern of the river. It is plausible to suggest from the above observations that these inferred faults provided significant structural control for the magmatism, sedimentation pattern and the flow pattern of the lower portion of river Hadejia in the study area.

The Pan- African period (750 - $550 \mathrm{Ma})$, represent the evolvement phase of the WCARS which include the Bornu basin. During this phase, the Pan- African crustal consolidation produced major lineaments and faults whose trends (i.e. NE-SW, NW-SE and ENE-WSW) formed precursor rift directions for future Cretaceous rifts (Genik, 1992).

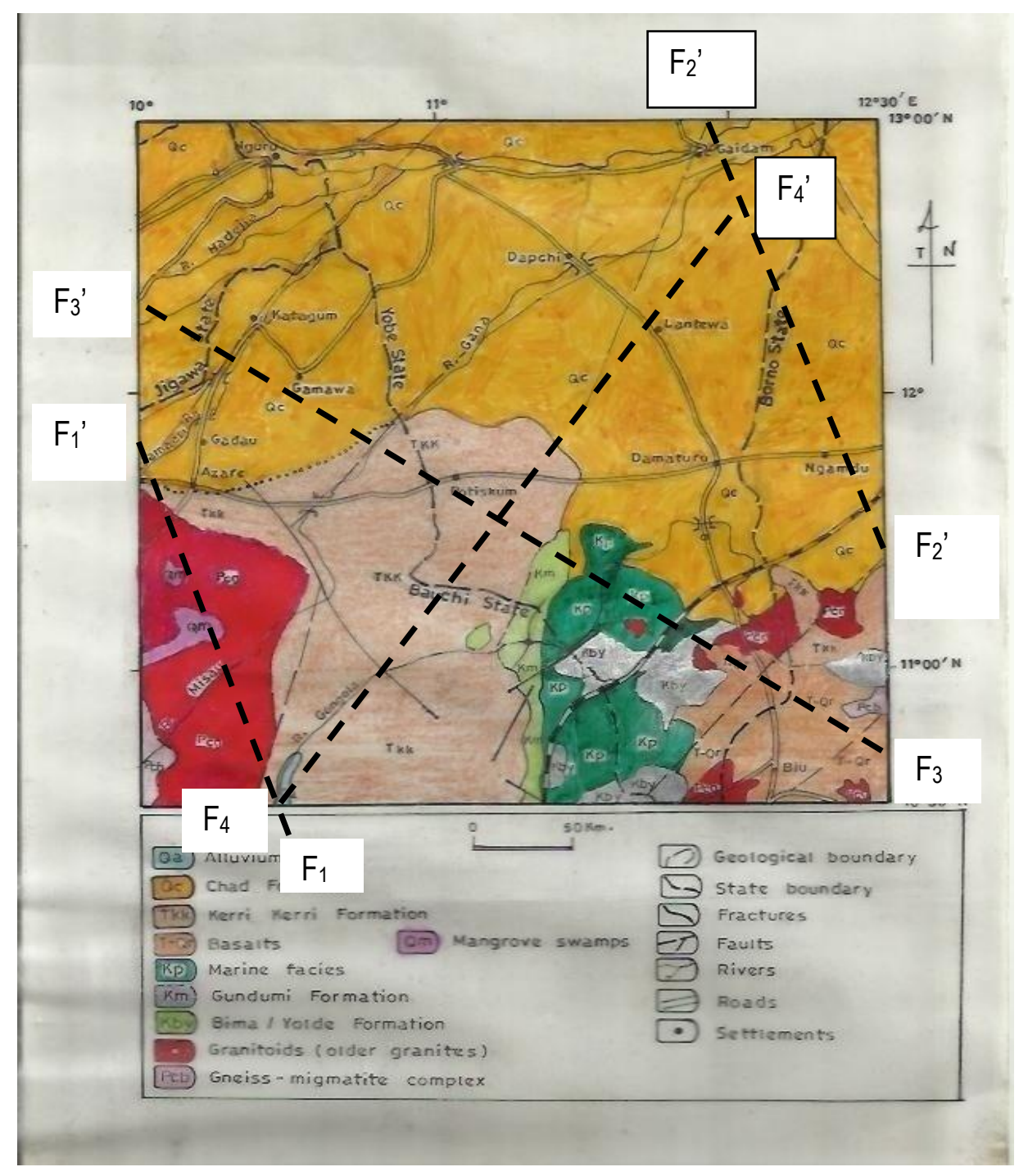

Figure 9: The inferred deep-seated faults superposed on the surface geology of the study area. 


\section{Nigerian Journal of Basic and Applied Science, (December, 2016), 24(2): 73-84}

The Early Cretaceous (130 - $98 \mathrm{Ma}$ ) represent the main phase of the rift development during which the separation between Africa and South America commenced with wrench fault zones extending from South America into the Gulf of Guinea and Africa utilizing the pre-existing zone of weaknesses associated with the Pan- African tectonic episode (Genik, 1992). Thus, the four deep-seated faults, whose trends correlate with the rejuvenated Early Cretaceous faults, were fundamental features associated with evolvement of the Bornu basin and not secondary features developed in response to the increasing strain in the basin. This agrees with the assertion of Lawal and Akaolisa (2011) whose work delineated two regional NW-SE lineaments in the eastern part of the Bornu basin and interpreted them as reflection of the major tectonic events associated with the development of the basin.

Finally, it is worth mentioning that the trends of the inferred lineaments in this study correlate with the trends of the structural features earlier inferred within Bornu basin and the adjacent Benue trough from previous studies (Ajaikaye et al., 1986; Avbovbo et al., 1986; lbe, 2000; Lawal and Akaolisa, 2011; Emmanuel and Augustine, 2012; Anudu et al., 2014; Sanusi and Likkason, 2015). This may reflect genetic and/or structural relationship between the Bornu basin and the Benue trough.

\section{CONCLUSIONS}

Detailed analysis of total-field aeromagnetic data over the entire western half of the Bornu basin and its adjoining areas were performed using the digital processing tools involving angular spectral analysis, upward continuation and lowpass filtering to accentuate the effects of deep-seated structures in the study area. Based on the application of the aforementioned techniques and the results obtained from the study, the following major conclusions are drawn:

The effect of upward continuation of magnetic field to a height of $40 \mathrm{~km}$ is similar to lowpass filtering of wavelengths $145 \mathrm{~km}$ in the study area.
The inferred deep-seated faults, including the two that bounded the study area, were interpreted to exert a fundamental structural control on the sedimentation pattern, magma ascension and river pattern in the study area.

The inferred deep-seated faults are not secondary features that were developed in response to increasing strain, but primary features that form an integral part in the evolvement of the study area.

The contour map of the residual magnetic field intensity values predominantly reflects the magnetic effects of shallow and intermediate sources.

Angular spectral analysis technique can be employed as an effective tool to delineate intracrustal lineaments.

\section{REFERENCES}

Affleck, J. (1963). Magnetic anomaly trends and spacing patterns. Geophysics, 28: $379-395$.

Ajakaiye, D. E., Hall, D. H., Miller, T. W., Verheigen, P. J. T., Awad, M. B and Ojo, S. B. (1986). Magnetic anomalies and tectonic trends in and around the Benue Trough. Nature, 319: 582 584.

Avbovbo, A. A., Ayoola, E.O. and Osahon, G. A. (1986). Depositional Structural Styles in the Chad Basin of Northeastern Nigeria. Bulletin of American Association of Petroleum Geologist, 70: $1787-1798$.

Anudu, G. K.,Randell, A. S. and MacDonald, D. I. M. (2014). Using high resolution aeromagnetic data to recognize and identify intrasedimentary volcanic rocks and geological structures across the Cretaceous middle Benue trough. Journal of African Earth Sciences, http://dx.doi.org/10.1016/i.jafrearsci.2013.11.0 05 .

Barber, W. (1965). Pressure water in the Chad formation of Bornu and Dikwa Emirates, Northeastern Nigeria. Bulletin of Geological Survey of Nigeria, 35: 32-46.

Bassey, N. E., Dike, E. F. C. and Likkason, O. K. (2012). Digital filtering of aeromagnetic maps for lineaments detection in Hawal basement complex of Hawal area, NE Nigeria. Journal of Mining and Geology, 48(1): 1-11. 
Bhattacharya, B. K. (1965). Two-dimensional harmonic analysis as a tool for magnetic interpretation. Geophysics, 30: $829-857$.

Claerbout, J. F. (1976). Fundamentals of Geophysical data processing with applications to petroleum prospecting. McGraw - Hill, New York.

Durotoye, B. (1976). Quarternary sediments of the Niger delta. In C.A.Kogbe (Ed.); Geology of Nigeria (pp 347- 357). Lagos, Elizabethan Publishing.

Emmanuel, E. and Augustine, C. (2012). Re-evaluation of hydrocarbon potentials ofeastern part of Chad basin, Nigeria: An aeromagnetic approach. Annual Convention and Exhibition, American Association of Petroleum Geologist, California, USA, Expanded Abstract. Pp 22 25.

Furon, R. (1963). Geology of Africa. London. Oliver and Boyd Publishing.

Genik, G. J.(1992). Regional framework and structural aspects of the rift basins in Niger, Chad and Central African Republic (C. A. R). In: Zeigler, P. A. (Ed.), Geodynamics of Rifting, Volume II. Case History Studies on Rifts: North and South America and Africa. Tectonophysics, 213; 169-185.

Hall, S. A. (1979). A total intensity aeromagnetic map of the Red Sea and its interpretation. Saudi Arabian Project Report (USGS): $275-260$.

Ibe, S. O. (2000). Analysis and interpretation of aeromagnetic data over eastern part of the Chad basin. An M.Sc dissertation submitted to Department of Physics, ABU, Zaria (Unpublished).

Kearey, P., Brooks, M. and Hill, I. (2002). An Introduction to Geophysical Exploration, 2nd edition, Blackwell Science, Pp $1-237$.

Lawal, K. M. (2005). Fractal magnetic modeling of the aeromagnetic data within the Chad basin of Nigeria. A Ph.D dissertation submitted to Department of Physics, ABU, Zaria (Unpublished).

Lawal, K. M. and Akaolisa, C. C. Z. (2011). Evidence of some major tectonic events in the Chad basin revealed from aeromagnetic studies. Nigerian Journal of Physics, 22(1): $14-20$.

Likkason, O. K. (2004). Application of digital processing tools to the analyses and structural interpretation of aeromagnetic data over the Middle Benue Trough, Nigeria. A Ph.D dissertation submitted to Department of Physics, ATBU, Bauchi (Unpublished).

Likkason, O. K. (2007). Angular spectral analysis of aeromagnetic data over the Middle Benue Trough, Nigeria. Journal of Mining and Geology, 13(1): $53-62$.

Likkason, O. K., Ajayi, C. O., Shemang, E. M. and Dike, E. F. C. (2005). Indication of fault expressions from filtered and Werner deconvolution of aeromagnetic data of the Middle Benue Trough, Nigeria. Journal of Mining and Geology, 41(2): $205-227$.

Matheis, G. (1976). Review of the Geology of the Chad Basin in Nigeria. In Kogbe, C. A. (Ed), Geology of Nigeria. Elizabethan Publishing Company, Lagos. Pp 287- 294.

Naidu, P. S. and Mathew, M. P. (1998). Analysis of geophysical potential fields. Elsevier Publishing Company, Amsterdam.

Obaje, N. G., Wehner, H., Hamza, H. and Scheeder, G. (2004). New geochemical data from the Nigerian sector of the Chad basin: implications on hydrocarbon prospectivity. Journal of African Earth Science, 38(5): 477 - 487.

Onyedim, G. C., Alagoa, K. D., Adedokun, I. O., Aderogba, A. A. and Ovuru, C. (2009). Mapping high-angle basement faults in the Middle Benue Trough, Nigeria from gravity inversion surface. Earth Science Research Journal, 13(2): 140 - 147.

Sanusi, Y. A. and Likkason, O. K. (2011). 2D radial spectral analysis of aeromagnetic data over parts of Chad basin, Nigeria. Nigerian Journal of Physics, 22(1): 29 - 37.

Sanusi, Y. A. and Likkason, O. K. (2015). Delineation of deep-seated structural features beneath western parts of Bornu basin and its adjoining areas using aeromagnetic data. Nigerian Journal of Physics, 26(1): $34-48$.

Spector, A. and Garnt, F. S. (1970). Statistical model for interpreting aeromagnetic data. Geophysics, 35: 293-302 